\title{
MATERNAL AND PERINATAL COMPLICATIONS OF SEVERE PREECLAMPSIA
}

\author{
Ritanjali Behera ${ }^{1}$, Arpika Aparajita Behera ${ }^{2}$
}

${ }_{1}^{1}$ Associate Professor, Department of Obstetrics and Gynaecology, MKCG Medical College, Berhampur.

2Postgraduate Student, Department of Obstetrics and Gynaecology, MKCG Medical College, Berhampur.

\author{
BACKGROUND \\ ABSTRACT \\ intrauterine growth restriction. \\ Aims and Objectives- \\ 1. To determine maternal outcome in severe preeclampsia. \\ 2. To determine foetal and neonatal outcome in severe preeclampsia.
}

Hypertensive disorders of pregnancy are a major cause of maternal morbidity and mortality. Preeclampsia is characterised as mild or severe. Features of severe preeclampsia include severe proteinuria, hypertension, symptoms of central nervous system dysfunction, hepatocellular injury, thrombocytopenia, oliguria, pulmonary oedema, cerebrovascular accident and severe

\section{MATERIALS AND METHODS}

This prospective, observational study was worked out in the Dept. of Obstetrics and Gynaecology, MKCG Medical College and Hospital, Berhampur, Odisha from 1st October 2016 to 30 th September 2017. Cases of severe preeclampsia were identified. Blood pressure measurements were done. Blood samples were collected for laboratory evaluation. Maternal complications such as eclampsia, HELLP syndrome, acute renal insufficiency, disseminated intravascular coagulation, placental abruption, cerebral and visual disturbance, oliguria, IUGR, pulmonary oedema etc. were recorded.

\section{RESULTS}

Among the cases of severe preeclampsia, most were in the age group of 21 - 30 years (56\%), were illiterate (57.8\%) and stayed in rural areas (72.9\%). Most of them belonged to lower socioeconomic status (41.3\%) followed by middle and majority were booked cases (70.6\%). Most common clinical feature was raised SBP (> 160) in 204 cases and DBP > 110 in 208 cases. Oedema was associated in $79.3 \%$ cases and rare feature like visual disturbances was seen in $3.8 \%$ of cases. Most of the maternal complications were due to development of pulmonary oedema (29.3\%) and most common foetal complication observed was acute foetal distress (24.1\%) followed by oligohydramnios (13.7\%).

\section{CONCLUSION}

The goals of therapy must always be the safety of the mother first and then consideration for optimum perinatal outcomes.

\section{KEYWORDS}

Maternal Complications, Pregnancy Outcome, Proteinuria, Severe Preeclampsia.

HOW TO CITE THIS ARTICLE: Behera R, Behera AA. Maternal and perinatal complications of severe preeclampsia. J. Evolution Med. Dent. Sci. 2018;7(10):1174-1177, DOI: $10.14260 /$ jemds/2018/268

\section{BACKGROUND}

Hypertensive disorders of pregnancy are a major cause of maternal morbidity and mortality.[1] These generally involve hypertension related conditions occurring primarily during pregnancy or may be pre-existing and persist during and/or after pregnancy.[2] Generally, hypertensive disorders of pregnancy are said to complicate $5 \%-10 \%$ of pregnancies and account for $10 \%-15 \%$ of maternal deaths globally.[3,4] The development of hypertension and proteinuria in pregnancy is usually due to preeclampsia, particularly in a primigravida.

Preeclampsia is characterised as mild or severe. Features of severe preeclampsia include severe proteinuria, hypertension and symptoms of central nervous system

'Financial or Other Competing Interest': None.

Submission 09-01-2018, Peer Review 14-02-2018,

Acceptance 21-02-2018, Published 05-03-2018.

Corresponding Author:

Dr. Arpika Aparajita Behera,

Room No. 112, PG Ladies Hostel,

MKCG Medical College,

Berhampur-760004, Odisha.

E-mail:dr.arpika1987@gmail.com

DOI: $10.14260 /$ jemds $/ 2018 / 268$ dysfunction, hepatocellular injury, thrombocytopenia, oliguria, pulmonary oedema, cerebrovascular accident and severe intrauterine growth restriction. Women with severe preeclampsia must be hospitalised to confirm the diagnosis, to assess the severity of the disease, to monitor the progression of the disease and to try to stabilise the disease.[5]

One of the rare effects of severe preeclampsia on the eye is sudden loss of vision due to involvement of the occipital cortex or the retina.[6] Subcapsular hepatic haematoma caused mainly by the development of disseminated intravascular coagulation is one of the rare complications experienced with severe preeclampsia and eclampsia.[7]

The goals of therapy must always be the safety of the mother first and then consideration for optimum perinatal outcomes. The only cure for severe preeclampsia is delivery.[8]

\section{Aims and Objectives}

1. To determine maternal outcome in severe preeclampsia.

2. To determine foetal and neonatal outcome in severe preeclampsia. 


\section{MATERIALS AND METHODS}

This prospective observational study was worked out in the Dept. of Obstetrics and Gynaecology, MKCG Medical College and Hospital, Berhampur, Odisha from 1st October 2016 to 30th September 2017.

Severe preeclampsia was defined as the presence of one or more of the following criteria: (a) Blood pressure (BP) Of $160 \mathrm{mmHg}$ or higher systolic or $110 \mathrm{mmHg}$ or higher diastolic on two occasions at least 6-h apart, while the patient is in bed rest; (b) Proteinuria of $5 \mathrm{~g}$ or higher in a 24-h urine specimen; (c) Oliguria of less than $500 \mathrm{~mL}$ in $24 \mathrm{~h}$; (d) Cerebral or visual disturbances; (e) Pulmonary oedema; (f) Epigastric or right upper quadrant pain; (g) Foetal growth restriction; (h) Symptoms such as persistent severe headache; (i) Medical complications involving acute renal insufficiency, hepatic haematoma or HELLP syndrome.

Patients were hospitalised in labour ward. On admission, blood pressure measurements were done. Blood samples were collected for laboratory evaluation. Maternal complications such as eclampsia, HELLP syndrome, acute renal insufficiency, disseminated intravascular coagulation, placental abruption, cerebral and visual disturbance, oliguria, IUGR, pulmonary oedema etc. were recorded.

Data regarding the demographic parameters, gestational age, persistent sign and symptoms, blood pressure measurement on admission, laboratory evaluation of blood samples (complete blood count, liver enzymes, creatinine, coagulation profile, platelet count) were recorded. Results were analysed using percentage and proportion.

\section{RESULTS}

In the study period of 12 months total 304 patients were admitted as cases of preeclampsia, out of which 232 were categorised as severe preeclampsia.

\begin{tabular}{|c|c|c|}
\hline Characteristics & $\begin{array}{c}\text { No. of Cases of Severe } \\
\text { Preeclampsia }\end{array}$ & $\%$ \\
\hline Age & 41 & \\
<20 years & 130 & 17.7 \\
21-30 years & 59 & 56.0 \\
31-40 years & 2 & 25.5 \\
>40 years & 98 & 0.8 \\
\hline Education & 134 & 42.2 \\
Literate & 169 & 57.8 \\
Illiterate & 63 & 72.9 \\
\hline Habitus & & 27.1 \\
Rural & 96 & \\
Urban & 74 & 41.3 \\
\hline Socio-Economic & 62 & 31.8 \\
Status & 164 & 26.9 \\
Low & 68 & 70.6 \\
Middle & High & 29.4 \\
\hline Antenatal Care & \multicolumn{2}{|c|}{} \\
Booked & Table 1. Demographic Parameters \\
Unbooked & \multicolumn{2}{|c|}{} \\
\hline \multicolumn{2}{|c|}{}
\end{tabular}

Among the cases of severe preeclampsia most were in the age group 21 - 30 years (56\%), were illiterate (57.8\%) and stayed in rural areas $(72.9 \%)$. Most of them belonged to lower socio-economic status $(41.3 \%)$ followed by middle and majority were booked cases $(70.6 \%)$.

\begin{tabular}{|c|c|c|}
\hline Characteristics & $\begin{array}{c}\text { No. of Cases of Severe } \\
\text { Preeclampsia }\end{array}$ & $\mathbf{\%}$ \\
\hline GA & 6 & \\
$<28$ weeks & 40 & 2.5 \\
28-34 weeks & 52 & 17.2 \\
34-36 weeks & 134 & 22.4 \\
$\geq 37$ weeks & 97 & 57.9 \\
\hline Parity & 41.9 \\
Nullipara & 55 & 23.7 \\
Primipara & 80 & 34.4 \\
Multipara & 204 & \\
Clinical Features & 208 & 87.9 \\
SBP > 160 & 202 & 90.0 \\
DBP > 110 & 184 & 87.0 \\
Proteinuria & 9 & 79.3 \\
Oedema & \multicolumn{2}{|c}{} \\
Visual Disturbances & Table 2. Clinical Characteristics \\
\hline \multicolumn{2}{|c}{} \\
\hline \multicolumn{2}{|c|}{} \\
\hline \multicolumn{2}{|c|}{} \\
\hline
\end{tabular}

Majority patients of severe preeclampsia were term pregnancies (57.9\%) followed by 34 - 36 weeks GA. Preeclampsia was found to be more common in nullipara patients (41.9\%). Most common clinical feature was raised SBP (> 160) in 204 cases and DBP > 110 in 208 cases. Oedema was associated in $79.3 \%$ cases and rare feature like visual disturbances was seen in $3.8 \%$ of cases.

\begin{tabular}{|c|c|c|}
\hline Investigation & No. of Cases & \% \\
\hline Raised AST/ALT & 188 & 81.0 \\
\hline Raised LDH & 192 & 82.7 \\
\hline $\begin{array}{c}\text { Raised Serum Uric } \\
\text { Acid }\end{array}$ & 172 & 74.1 \\
\hline Abnormal RFT & 158 & 68.1 \\
\hline \multicolumn{2}{|c|}{ Table 3. Investigations } \\
\hline
\end{tabular}

Table 3 shows among all patients of severe preeclampsia $81 \%$ had raised serum liver enzymes, serum LDH was raised in $82.7 \%$ of cases, serum uric acid $>4.5$ was found in $74.1 \%$ and abnormal levels of serum urea and creatinine was seen in $68.1 \%$ cases.

\begin{tabular}{|c|c|c|}
\hline Anticonvulsant & No. of Cases & $\mathbf{\%}$ \\
\hline Inj. Magnesium sulphate & 232 & 100 \\
\hline Antihypertensive & & \\
\hline Labetalol & 226 & 97.4 \\
\hline Labetalol + Nifedipine & 45 & 19.3 \\
\hline Miscellaneous & & 31.0 \\
\hline Hydrocortisone & 72 & 27.5 \\
\hline Furosemide & 64 & 25.0 \\
\hline Nebulisation & 58 & \\
\hline \multicolumn{2}{|c|}{ Table 4. Treatment Modalities } \\
\hline
\end{tabular}

All cases received Inj. Magnesium sulphate as prophylactic anticonvulsant. Hypertension was controlled by labetalol (IV and oral) in 97.4\% and addition of nifedipine was required in $19.3 \%$ cases. Hydrocortisone was used in $31 \%$, furosemide in $27.5 \%$ and nebulisation with salbutamol and budesonide was required in $25 \%$ cases.

\begin{tabular}{|c|c|c|}
\hline Complications & No. of Cases & $\mathbf{\%}$ \\
\hline Eclampsia & 14 & 6.0 \\
\hline Abruptio placentae & 16 & 6.8 \\
\hline Acute renal failure & 10 & 4.3 \\
\hline DIC & 2 & 0.8 \\
\hline HELLP syndrome & 2 & 0.8 \\
\hline
\end{tabular}




\begin{tabular}{|c|c|c|}
\hline Pulmonary oedema & 68 & 29.3 \\
\hline Low platelet count & 18 & 7.7 \\
\hline Respiratory failure & 4 & 1.7 \\
\hline Mode of Delivery & & \\
\hline VD & 50 & 21.6 \\
\hline LSCS & 178 & 76.7 \\
\hline Hysterotomy & 4 & 1.7 \\
\hline Outcome & & \\
\hline Survived & 220 & 94.9 \\
\hline \multicolumn{2}{|c|}{ Died Table 5. Maternal Complications } \\
\hline
\end{tabular}

Most of the maternal complications associated with severe preeclampsia was due to development of pulmonary oedema $(29.3 \%)$. Low platelet count $(<50,000)$ was seen in $7.7 \%$ cases. The occurrence of abruptio placentae and eclampsia was in $6.8 \%$ and $6.0 \%$, respectively. The patients of severe preeclampsia that developed eclampsia, mostly it occurred in post-partum period. Respiratory failure in $1.7 \%$ and both DIC and HELLP syndrome were seen in $0.8 \%$ cases.

Most common mode of delivery was caesarean section (76.7\%) followed by vaginal delivery (21.6\%). Hysterotomy was done only in 4 cases.

Out of all patients of severe preeclampsia, only 12 patients died due to severe complications.

\begin{tabular}{|c|c|c|}
\hline Foetal Complication & No. of Cases & \% \\
\hline Still Birth & 17 & 7.3 \\
\hline IUGR & 21 & 9.0 \\
\hline Oligohydramnios & 32 & 13.7 \\
\hline Acute Foetal Distress & 56 & 24.1 \\
\hline Neonatal Complication & & \\
\hline Low APGAR Score & 62 & 26.7 \\
\hline Prematurity & 152 & 65.5 \\
\hline NICU Referral & 127 & 54.7 \\
\hline Early Neonatal Death & 14 & 6.0 \\
\hline \multicolumn{2}{|c|}{ Table 6. Foetal and Neonatal Complications } \\
\hline
\end{tabular}

The most common foetal complication observed was acute foetal distress $(24.1 \%)$ followed by oligohydramnios $(13.7 \%)$. IUGR was seen in $9.0 \%$ and still birth occurred in $7.3 \%$ cases. 127 neonates were referred to NICU (54.7\%). Among neonates $65.5 \%$ were premature and $26.7 \%$ were born with low APGAR score, both at 1 and 5 minutes. 14 cases died in early neonatal period.

\section{DISCUSSION}

Most patients of severe preeclampsia were in age group 21 30 years, which correlates with Ngowa et al (2015).[9] 72.9\% belonged to rural area as in Mohammad Ahadi et al (2015).[10] Most of them were booked case (70.6\%) as in Ngwenya et al(2017).[11]

Among clinical characteristics most were term pregnancies (57.9\%), which is in accordance with Ngowa et al (2015) ${ }^{[9]}$ and 41.9\% were nullipara as in Mohammad Ahadi et al (2015).[10] SBP > 160 was seen in $87.9 \%$ and DBP > 110 in $90 \%$ cases. Association with oedema was found in $25.8 \%$ cases. All these findings were in agreement with Mohammad Ahadi et al (2015).[10] Visual disturbances were seen in 3.8\%, as in Nankali et al (2013).[12]

In the present study the incidence of pulmonary oedema is very high $(29.3 \%)$ as compared to literature, because most patients come at a late stage to our Institution as referred cases. Eclampsia was seen in $6 \%$ and abruptio placentae in 6.8\%, as in Nankali et al (2013).[12]

Caesarean section was the most common mode of termination of pregnancy, which correlates with Ngwenya et al (2017).[11]

Still birth was seen in $26.7 \%$, IUGR in $9.0 \%$ and low APGAR score in $26.7 \%$ which was in concordance with Ngowa et al(2015).[9] Prematurity was seen in 65.5\% and NICU referral in 54.7\% cases, as in Ngwenya et al (2017).[11]

\section{CONCLUSION}

Women with severe preeclampsia have a greater chance to develop maternal complications and have a poor neonatal outcome, especially if they had not received prenatal care. The risk factor in women with gestational hypertension associated with maternal complications and poor pregnancy outcome was slight proteinuria that may lead to a greater likelihood of DIC and placental abruption. Risk factors associated with severe preeclampsia were prenatal care status, advanced maternal age, SBP and DBP, and significant proteinuria. In addition, with regard to the effect of gestational hypertension in patients with mild proteinuria, maternal complications became the only significant factor that contributed to pregnancy outcome.

To tackle these figures on maternal, foetal and neonatal health, governments in low-resource settings must focus on development and enabling women to be in an economic position to access health care easily. There should be affordable and accessible antenatal care services where women are taught about the dangers of preeclampsia/eclampsia, so that they present early to hospitals. This would help prevent complications and unnecessary loss of lives.

Neonatal care facilities need to be improved to improve the outcomes from the units. Neonatal health must be placed on the global agenda and given the same attention as maternal health. Global efforts must involve developmental aid and debt relief to poor countries, so that these countries can channel the funds to women and neonatal health issues.

\section{REFERENCES}

[1] Seyom E, Abera M, Tesfaye M, et al. Maternal and fetal outcome of pregnancy related hypertension in Mettu Karl Referral Hospital, Ethiopia. J Ovarian Res 2015;8(1):10.

[2] Berhan Y, Endeshaw G. Maternal mortality predictors in women with hypertensive disorders of pregnancy: a retrospective cohort study. Ethiop J Health Sci 2015;25(1):89-98.

[3] Vest AR, Cho LS. Hypertension in pregnancy. Curr Atheroscler Rep 2014;16(3):395.

[4] Duley L. The global impact of pre-eclampsia and eclampsia. Semin Perinatol 2009;33(3):130-7.

[5] Brichant G, Dewandre PY, Foidart JM, et al. Management of severe preeclampsia. Acta Clin Belg 2010;65(3):163-9.

[6] Swende TZ, Abwa T. Reversible blindness in fulminating preeclampsia. Ann Afr Med 2009;8(3):189-91. 
[7] Abundis EM, Vazquez JA, Gonzalez AV, et al. Subcapsular hepatic hematoma in severe postpartum pre-eclampsia. Presentation of a case. Ginecol Obstet Mex 1989;57:325-8.

[8] Jantasing S, Tanawattanacharoen S. Perinatal outcome in severe preeclamptic women between 24-33(+6) weeks gestation. J Med Assoc Thai 2008;91(1):25-30.

[9] Ngowa JDK, Kasia JM, Alima J, et al. Maternal and perinatal complications of severe preeclampsia in three referral hospitals in Yaoundé, Cameroon. Open Journal of Obstetrics and Gynecology 2015;5(12):72330.
[10] Ahadi SS, Yoshida Y, Rabi M, et al. Clinical features, current treatments and outcome of pregnant women with preeclampsaia/eclampsia in northern Afghanistan. Nagoya J Med Sci 2015;77(1-2):103-1.

[11] Ngwenya S. Severe preeclampsia and eclampsia: incidence, complications, and perinatal outcomes at a low-resource setting, Mpilo central hospital, Bulawayo, Zimbabwe. Int J Womens Health 2017;9:353-7.

[12] Nankali A, Malek-Khosravi S, Zangeneh M, et al. Maternal complications associated with severe preeclampsia. J Obstet Gynecol of India 2013;63(2):112-5. 